\title{
UMA LADY MACBETH. DA PEDAGOGIA AO PALCO
}

\author{
Heloise Baurich Vidor ${ }^{1}$
}

Resumo

Este artigo pretende discutir como procedimentos da metodologia do drama na educação, ${ }^{2}$ usualmente desenvolvidos no âmbito da pedagogia teatral, foram tomados como ponto de partida para a criação do espetáculo solo uma lady MACBETH. ${ }^{3}$ A ideia do espetáculo surgiu a partir da experiência com o texto de Shakespeare num processo coletivo de drama, no qual um dos focos de investigação foi a experimentação com a estratégia de mediação própria desta metodologia, chamada professorpersonagem. A ideia do professor-personagem como condutor da ação definiu o formato do espetáculo e trouxe consigo a perspectiva de associação entre teatro e pedagogia.

Palavras-chave: apedagogia teatral, atuação, processo criativo, MACBETH, drama.

\section{Abstract}

This paper aims to discuss how procedures of methodology of drama in education, usually developed under the theatrical pedagogy, were taken as a starting point for the creation of the performance uma lady $M A C B E T H$. The idea of the performance emerged from the experience with the text of Shakespeare in a collective process of drama, in which one of the focus of research was experimenting with his own mediation strategy this methodology, called teacher in character. The idea of teacher in character as driver of action defined the format of the performance and brought the prospect of association between theatre and pedagogy.

Keywords: theatrical pedagogy, acting, creative process, MACBETH, drama. 


\section{As ideias que movem esta trajetória...}

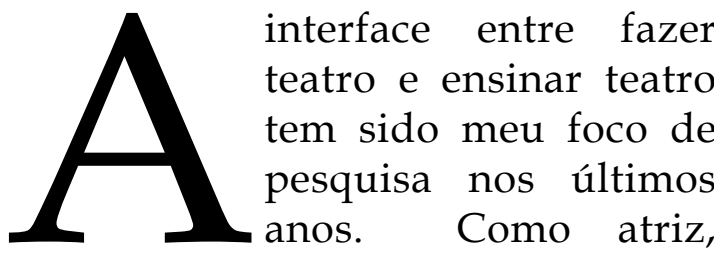
professora de teatro e formadora de professores que sou, tenho procurado superar o preconceito que ainda se faz presente quando termos como 'pedagógico' ou 'educativo' aparecem como parceiros de 'artístico'. Como forma de resistência e enfrentamento a esta questão procuro encontrar caminhos de aproximação entre 'arte e docência' e 'professor e artista' no próprio ato docente e, agora, na criação de um espetáculo.

O contato com o drama e com uma de suas principais estratégias de mediação, o teacher in role, em pesquisa realizada no âmbito de pós-graduação, ${ }^{4}$ foi $\mathrm{o}$ caminho de abertura para esta interface, pois me fez vislumbrar a possibilidade de aproximação entre os papéis do professor e do ator, visto que o teacher in role é quando o professor assume outro papel social (que não o de professor) para interagir com os alunos num processo de drama. Um médico, um advogado, um político, podem ser alguns dos papéis que vão provocar e desafiar os alunos na criação da narrativa ficcional.

Os estudiosos e praticantes do drama como Cecily O’Neil (1995) ou Judith Ackroyd (2004) insistem em afirmar que para utilizar esta estratégia não é necessário que o professor tenha

1 Heloise Baurich Vidor é atriz e professora do Departamento de Artes Cênicas da UDESC, na área de Pedagogia do Teatro. Doutoranda em Pedagogia Teatral e Teatro e Educação no PPGAC/ECA/USP

2 Metodologia inglesa de ensino do teatro, também conhecida como drama, process drama ou drama educação. Neste texto, sempre que a palavra 'drama' aparecer em itálico é porque se refere à metodologia mencionada.

3 Este espetáculo foi financiado através do Edital de Cultura da UDESC/2010.

4 Mestrado realizado no PPGT/UDESC e transformado em livro VIDOR, H.B. Drama e Teatralidade: o ensino do teatro na escola. Porto Alegre: Mediação, 2010. habilidades de atuação. Mas se o mesmo é também um ator, por que não lançar mão de suas habilidades e incrementar o jogo cênico com o aluno?

O jogo, proposto e executado pelo professor-ator, abre, especialmente no campo da aula de teatro, a possibilidade de aproximação dos alunos às particularidades do trabalho do ator, tanto no que diz respeito à representação de personagens no próprio ato pedagógico, quanto aos recursos técnicos utilizados para a composição. Neste sentido, o teacher in role ganhou no contexto brasileiro a tradução de professorpersonagem, ${ }^{5}$ pois a palavra 'personagem' remete ao universo do teatro e aponta para uma dupla possibilidade, pois 'no papel' o professor interage com os alunos via improvisação e 'no personagem' traz o sentido de representação de um texto e a visão de mundo do autor. (VIDOR, 2010)

$\mathrm{O}$ trânsito entre o professor no papel social e no personagem, que esteve na base do trabalho em sala de aula, foi o que me interessou como proposta de deslocamento para o âmbito de um espetáculo. E, para a presente discussão, meu interesse é analisar quais elementos do processo se mantiveram no espetáculo e como os mesmos foram re-apropriados.

\section{As ideias que nortearam a criação do espetáculo...}

$\mathrm{Na}$ construção da narrativa ficcional gerada pelo drama, em uma situação de ensino aprendizagem, o aluno, quando observa o professor-personagem, reconhece que é o professor em 'situação de representação' e, com isso, passa a jogar com as possibilidades que se delineiam entre ficção e realidade. E se a sala de aula for o próprio palco, como pode se dar o jogo pedagógico via professor-personagem? Será que o público reconhece que é o ator em 'situação de aula'?

5 Tradução proposta por CABRAL, Beatriz. Drama como método de ensino. São Paulo: Hucitec, 2006. 
Estes questionamentos vieram à tona a partir da realização de um processo de drama que levou o nome de $D a$ Ambição à Loucura, realizado a partir de Macbeth de Shakespeare como pré-texto, com alunos da universidade. ${ }^{6} \mathrm{O}$ objetivo principal foi verticalizar a diferenciação entre o professor no papel social e professorpersonagem e observar aspectos decorrentes desta diferenciação. ${ }^{7}$ A opção foi que ambos fossem realizados por professores distintos na tentativa de delinear precisamente os limites de cada função. A mim coube trazer a personagem que, neste caso, foi Lady Macbeth, via 'professor-personagem' e Beatriz Cabral assumiu os papéis sociais - governanta dos Macbeths, mensageiro e bruxas. Apesar de serem intervenções pequenas da personagem, me pareceu fundamental que a composição fosse elaborada, pois estas intervenções teriam um papel chave para o estabelecimento da atmosfera dramática junto aos participantes, além de estabelecerem o contraste entre o personagem e o papel social.

Desta forma, a preparação exigiu um número razoável de ensaios que visavam desde o decorar dos textos até um refinamento no trabalho de composição corporal/vocal. Outro foco de preparação foi o trabalho com a apropriação e naturalização do texto shakespereano, já que optamos por manter a tradução em versos, de modo a potencializar as nuances poéticas e imagéticas, tão presentes nos textos do autor inglês. Além destes aspectos, a composição da personagem ganhou maior acabamento devido à utilização de figurinos e objetos que pudessem colaborar com o impacto visual das aparições de Lady Macbeth - carta em papel envelhecido, sangue

6 Este experimento fez parte das ações do projeto de pesquisa Formas de Apropriação do Texto na Escola desenvolvido por mim junto ao Departamento de Artes Cênicas do CEART/ UDESC (2009-2011).

7 Parte dos resultados do experimento foram comunicados na V Reunião Científica da ABRACE/ 2009 na ECA/USP, com o título: Lady Macbeth em cena: o professor-personagem e a apropriação da literatura dramática no processo de drama. falso nas mãos depois do assassinato de Duncan, figurino remetendo à época foram produzidos para este processo. ${ }^{8}$

Assim, o contato inicial com o texto para a criação do processo de drama proporcionou a leitura, a discussão e a seleção de situações da peça que estariam presentes como foco do processo, sem um estudo aprofundado dos personagens. Neste sentido, a preparação e inserção da personagem de Lady Macbeth no drama, pode-se dizer que foi um exercício de improvisação, gerado pelas linhas gerais da personagem e com a enunciação de fragmentos do texto original.

O jogo com o professor-personagem, a cada experimento, me faz constatar sua eficiência como instrumento de mediação para o envolvimento do aluno com questões da linguagem do teatro, de forma lúdica e impactante, e também se reforça como um elemento desafiador para o professor, já que abala as estruturas muitas vezes solidificadas da relação professor/ aluno, pois ambos agem de forma conjunta no espaço de jogo. Mas o que despertou minha curiosidade e entusiasmo nesta experiência em particular foi vislumbrar que esta estratégia poderia servir como eixo para trazer o texto de Macbeth, com toda a sua complexidade, riqueza de detalhes e acontecimentos, num formato que conjugasse o cênico, o poético, o pedagógico e o sintético.

Com o simples - ou não tão simples - jogo estabelecido pelo professorpersonagem, o professor-ator poderia, com um formato espetacular que se inspirasse no que conhecemos como aula-espetáculo, trazer a fábula, trazer os personagens com toda a intensidade emocional que lhes são peculiares, apontar questões do texto para reflexão e contextualização, remeter o espectador à

80 processo foi realizado de maneira concentrada - quatro horas aulas semanais, durante duas semanas - e devido ao seu impacto junto aos participantes, alunos e professores, estes decidiram retomá-lo de modo a organizar um roteiro com os "melhores momentos" e/ou "momentos chaves" do processo e apresentá-lo ao público como uma finalização da disciplina. 
época do texto, ao universo elizabethano, pela própria via poética, artística. Esta foi a minha ambição como professora-atriz.

$\mathrm{O}$ envolvimento com o texto de Skakespeare, gerado a partir do experimento cênico com o drama atrelado à sua possibilidade de desdobramentos em ocasiões como uma performance ou espetáculo levou à criação do projeto de montagem de um espetáculo solo, que fosse atuado pela professora-atriz. Assim, conjugar o professor na situação de aula e professor-personagem representando uma situação dramática foi o desafio central para a mim, e que se sintetizou na seguinte pergunta: como preservar o jogo entre 'ser o professor' e 'representar os personagens', explicitamente na cena, mantendo o sentido pedagógico e poético, que esteve presente na sala de aula, também no espetáculo?

\section{Os caminhos movediços do percurso...}

O processo de drama com Macbeth como pré-texto havia deixado alguns pontos de partida para o projeto de criação do espetáculo, que partiu do professor-personagem, e seria realizado por uma única professora-atriz em cena. Esta não é uma condição para o jogo com o professor-personagem, ou seja, outros participantes poderiam estar no espetáculo, mas aqui foi uma opção, visto o objetivo da pesquisa: verticalização e experimentação com esta estratégia e seu deslocamento do processo pedagógico em sala de aula para o palco.

O que eu tinha de concreto a partir do processo com os alunos eram, de minha parte, as pequenas cenas que havia criado para o drama - parte da cena da carta (Cena V do Ato 1), primeira hesitação da Lady após o assassinato (Cena II do Ato 3), e a cena da loucura (Cena I do Ato 5) - e de parte do processo coletivo as fortes imagens trazidas pelo grupo - a seqüência de luta dos guerreiros, os rituais das bruxas com as falas e cantos bruxólicos, os diferentes clãs que traziam a ambientação palaciana e a cena onde um busto de costureira representava Macbeth com sua voz (em off) mostrando sua obsessão sanguinária; finalizando com a cena da "floresta se aproximando do castelo" e a cabeça de Macbeth sendo oferecida ao público/povo escocês em uma bandeja de prata.

Depois de um período de acomodação entre a experiência do drama e a criação do projeto do espetáculo, acreditava que era viável realizar o que estava intuindo, ou seja, que o professor-personagem daria conta de estabelecer o jogo artístico e pedagógico, mas precisaria de parceiros, pois o desafio era grande. Este foi um momento importante na trajetória, pois a ideia inicial advinda do drama, que era um ponto de partida para mim, passou a dialogar com a concepção da direção, que desconhecia o processo.

Ainda que optar pela presença de um diretor pudesse por em risco a ideia inicial do projeto, para mim, era fundamental uma equipe que ajudasse nesta transposição. Assim o trabalho se configurou a partir do diálogo com o diretor, e sua concepção para aquela proposta, além deuma diretora deatuação, uma preparadora vocal, um instrutor de karatê, e posteriormente, um cenógrafo, uma criadora musical, uma figurinista, um iluminador e um produtor. ${ }^{9}$

A ideia do trabalho colocada aos parceiros de criação foi: vamos criar um espetáculo solo, onde a atriz-professora de teatro apresenta para a platéia a fábula de Macbeth, intercalando momentos de "aula expositiva" com momentos em que "atua a cena". Entre uma cena e outra, avança na narrativa, usando alguns elementos didáticos que

90 espetáculo foi dirigido por Edélcio Mostaço e a equipe de criação assim composta: Cláudia Sachs fez a direção de ator, Bárbara Biscaro, a preparação vocal, Professor Gilberto, instrutor de karatê, Fernando Mares, o cenário, Zilá Muniz, o figurino, Renata Swoboda, a trilha sonora, Daniel Olivetto foi o responsável pela iluminação, e Harmônica Arte e Entretenimento, pela produção. 
possam facilitar a compreensão, pela audiência, de uma fábula tão complexa e cheia de detalhes.

Os elementos de cena foram escolhidos a partir da perspectiva da aula de teatro e de recursos didáticos: figurino - roupa de ensaio preta e confortável; objetos cênicos e adereços que ajudassem a esclarecer a situação da ficção e os diferentes personagens Macbeth: touca de couro e coroa; Bruxa: capa e punhal; Lady Macbeth: turbante e xale; cenário - uma cadeira, cabides e um flip-chart, todos com acabamento rústico, com ares medievais; luz e música - criação de atmosfera dramática, ajudando a delinear os momentos das personagens e luz geral trazia o contraste para o momento 'da aula'.

A estrutura dramatúrgica, criada e recriada ao longo do processo, procurou colocar em perspectiva três aspectos centrais: a peça de Shakespeare em si / as questões éticas e sua contextualização / o formato: misto de aula e espetáculo. E decorrente destes aspectos, outras questões surgiram para mim: Qual é o objeto da aula? Quem é a professora? A construção da personagem deve estar explícita? $\mathrm{O}$ artístico está somente nos momentos em que se representa? A opção foi por estabelecer as seguintes matrizes que relacionadas com o drama traçariam o seguinte paralelo: 1. Professora-atriz - professor no papel social; 2. Lady Macbeth - professor- personagem; 3. Macbeth - professor-personagem; 4. Bruxa / personagem coletivo.

Aqui vale ressaltar uma mudança importante proposta pelo diretor do espetáculo e que se diferenciou do drama: a opção por trazer Macbeth e a Bruxa como personagens representados pela professora, além de Lady Macbeth. Este foi um desafio a mais para mim como atriz, mas que ajudou a potencializar ainda mais a estratégia, pois além de entrar e sair dos personagens num trânsito explícito, eram três personagens diferentes entre si.
Em termos de atuação, o trabalho preparatório contou com aulas de karatê, preparação com exercícios da técnica de Jacques Lecoq e trabalho vocal. O percurso foi traçado da seguinte maneira: 1. criar o mundo ficcional / as matrizes das diferentes personagens; 2. pensar em como trabalhar com a professoraatriz. E aqui uma questão sempre me acompanhava: será que a 'professoraatriz' tem que ser criada ou sou eu mesma no meu papel social de professora de teatro, já conhecido?

\section{Pensamentos vindouros...}

Em uma lady MACBETH, a formação de uma equipe de criação garantiu a qualidade de acabamento da proposta sem comprometer a ideia inicial da aula - misto de aula e espetáculo em caráter processual. Este aspecto foi fundamental, pois havia a preocupação em aproximar o público da trama, em mostrar aspectos da construção de personagens pelo ator e o trânsito entre eles, em envolver o espectador com a aula, trazer a poesia de Shakespeare, trazer elementos históricos do teatro elizabethano. A preocupação com o refinamento dos detalhes no processo pedagógico também é fundamental para o envolvimento dos alunos com a proposta em qualquer contexto, seja profissionalizante ou não (escola, comunidades, ONGs).

Na situação de ensino, um aspecto que observo no deslocamento da estratégia do professor-personagem para um espetáculo é a questão do 'tempo' em que as coisas acontecem. Numa sala de aula, o professorator, quando se utiliza da estratégia o faz como uma pequena intervenção, algo rápido, intenso e pontual, que demarca bem o inicio e o fim, ou seja, a entrada e saída do papel ou personagem. Mas na situação do espetáculo, o tempo foi alterado e, por conseguinte, a intensidade de cada momento de representação, bem como sua transição. 
$\mathrm{Na}$ situação de aula esta transição muitas vezes acaba sendo codificada e, de certa forma, brusca na realização, devido à dificuldade gerada pelo grande número de alunos participantes. No espetáculo, as entradas e saídas de cada cena da peça demarcadas pelo trânsito entre os personagens da fábula - que foram três: bruxa, Lady Macbeth e Macbeth, muitas vezes intermediados pela professora - foram sutilizados, diluindo e construindo o espaço dramático sem ressaltar convenções. A música, o figurino e a luz acentuavam a atmosfera dramática dos personagens.

Ainda na aula, o jogo do professor de entrar e sair dos personagens atrai o aluno, sendo intervenções curtas com posterior comentário do professor in role sobre o ocorrido. Sem o comentário, ou seja, sem o retorno do professor, a mediação e o potencial da estratégia ficam enfraquecidos. A surpresa causada por novos personagens, a surpresa causada pelas diferentes formas de abordar as cenas, o impacto dos figurinos e objetos, também diferenciados a cada cena, além da atmosfera estabelecida pela música, são os elementos que podem incrementar a aula e que também estiveram no espetáculo, visando manter a atenção do espectador. No espetáculo, entretanto, a professora não comentava a cena ocorrida, mas retomava a história e seguia com os acontecimentos, preparando o espectador para uma nova a parição dos personagens.

Finalmente, o processo de drama é caracterizado pela interação entre o professor in role e os participantes, em interface com os momentos do professorpersonagem (que não visa a interação), sendo que ambas as interferências são curtas e pontuais. No espetáculo, a interação direta com o público aconteceu apenas em um único momento - quando a professora entrega papéis ao publico para que respondam a uma pergunta por ela realizada. Este foi o único momento em que o 'aqui agora' preponderou e fez com que a atriz interagisse concretamente com os espectadores.

\section{As considerações que não são finais...}

Colocar em contraste o cotidiano e o espetacular é o ponto chave da estratégia professor-personagem, tanto para a sala de aula quanto para o espetáculo. Pelo jogo do proftessor-ator, a fábula de Shakespeare, os conteúdos históricos e poéticos, a poesia do texto, enfim, todos estes elementos foram dispostos de modo não convencional e lúdico, além dos aspectos relacionados à gradação da atuação, que pode variar de um extremo a outro, e que é regida pelo professor-ator.

$\mathrm{O}$ formato compacto de uma lady $M A C B E T H$ surgiu a partir da escolha de colocar a estratégia do 'professorpersonagem' como eixo articulatório dos elementos da cena. Se no espetáculo foi o professor-personagem em jogo com o professor no papel social que possibilitou, em linhas gerais, a apropriação do texto de Shakespeare, isto indica que na sala de aula, ele também pode funcionar como um ponto de abertura para que aspectos presentes na cena teatral contemporânea cruzem os muros da escola.

O processo de criação do espetáculo lidou com o desafio de pensar em formas onde, o professor de teatro, sendo também um ator, possa atuar efetivamente, de modo a propor procedimentos e/ou situações que, sejam ao mesmo tempo, pedagógicas e poéticas, na sala de aula e no palco. Esta associação de campos está no foco de discussão de muito teóricos da arteeducação, que trabalham com os conceitos de artista-docente ou professor-artista, tais como Cabral (2006, 2010), Marques (2001, 2003), Strazzacappa (2006), Icle (2002, 2010), entre outros, e que acreditam que as diferenças nas atividades configuram-se no contexto e, por isso, não deve haver uma visão dissociativa entre arte e pedagogia.

No campo do ensino do teatro, os procedimentos de mediação do drama na educação, professor no papel social e professorpersonagem, favorecem a aproximação destas esferas, num mesmo espaço-tempo, colocando desafios artísticos e pedagógicos para o docente e para o artista que ali se juntam, seja na sala de aula ou no palco. 


\section{Referências bibliográficas}

ACKROYD, J. Role Reconsidered - a reevaluation of the relationship between teacher in role and acting. Staffordshire: Trentham Books Limited, 2004.

ARNOULD, P. Esoterisme de Shakespeare. Paris: Mercure de France, 1955.

CABRAL, B. Drama como método de ensino. São Paulo: Hucitec, 2006.

A Estética do dissenso em processos coletivos. In: NAVAS, C.; ISAACSSON, M.; FERNANDES, S. (Orgs.) Ensaio em cena. Salvador. ABRACE; Brasília. CNPQ, 2010.

CAMPBELL, L. B. Shakespeare's tragicheroes. London: University Paperbacks, 1930.

HEATHCOTE, D. The Fight for Drama - The Fight for Education - Keynotes speeches by Edward Bond $\mathcal{E}$ Dorothy Heathcote. From the NATD Conference October 1989. Edited and introduce by Edward Bond. Newcastle upon Tyne, National Association for Teaching of Drama, 1990. ICLE, G. Teatro e construção de conhecimento. Porto Alegre: Mercado Aberto, 2002. . Pedagogia teatral como cuidado de si. São Paulo: Hucitec, 2010.

LINKLATER, K. Freeing Shakespeare's voice. London: Nick Hern Books. 1992.

MARQUES, I A. Ensino da dança hoje - textos e contextos. São Paulo: Cortez, 2001.

Cortez, 2003. A dança na escola. São Paulo:

O'NEILL, C. Drama Worlds - A framework for process-drama. Portsmouth: NH. Heinemann, 1995.

SHAKESPEARE, W. Shakespeare de A a Z: livro das citações. Seleção de Sérgio Faraco. Porto Alegre: LPM, 1998. Macbeth. Tradução de Manuel Bandeira. São Paulo: Ed. Brasiliense, 1989. STRAZZACAPPA, M. Entre a arte $e$ a docência. Campinas: Papirus, 2006.

VIDOR, H. Drama e Teatralidade: o ensino do teatro na escola. Porto Alegre: Editora Mediação, 2010.

WATKINS, R. On Producing Shakespeare. London: Michael Joseph, 1951. 